\title{
Photosensitive Yb-Doped Germanophosphosilicate Artificial Rayleigh Fibers as a Base of Random Lasers
}

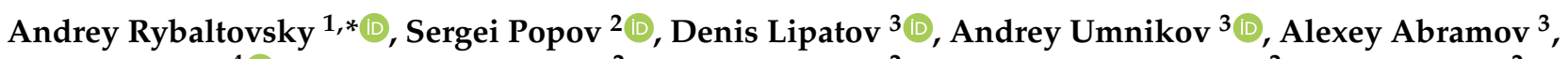 \\ Oleg Morozov 4 ${ }^{\circledR}$, Dmitry Ryakhovskiy ${ }^{2}$, Viktor Voloshin ${ }^{2}$, Alexander Kolosovskii ${ }^{2}$, Igor Vorob'ev ${ }^{2}$, \\ Oleg Butov 1 (1D and Yuriy Chamorovskiy ${ }^{2}$
}

1 Kotelnikov Institute of Radioengineering and Electronics, Russian Academy of Sciences, St. Mokhovaya 11-7, 125009 Moscow, Russia; obutov@mail.ru

2 Kotelnikov Institute of Radioengineering and Electronics (Fryazino Branch), Russian Academy of Sciences, pl. Akad. Vvedenskogo 1, 141190 Fryazino, Russia; sergei@popov.eu.org (S.P.); dryh97@mail.ru (D.R.); v.voloshin@bk.ru (V.V.); kolos_ao@mail.ru (A.K.); infosiv@fryazino.net (I.V.); yurichamor@gmail.com (Y.C.)

3 G. G. Devyatykh Institute of Chemistry of High-Purity Substances, Russian Academy of Sciences, St. Tropinina 49, 603951 Nizhny Novgorod, Russia; lidenis@yandex.ru (D.L.); umkand@yandex.ru (A.U.); abramovan84@mail.ru (A.A.)

4 Department of Radiophotonics and Microwave Theory, Kazan National Research State University Named after A.N. Tupolev-KAI, 31/7 Karl Marx St., 420111 Kazan, Russia; microoil@mail.ru

* Correspondence: rybaltovsky@yandex.ru; Tel.: +7-916-164-4405

check for updates

Citation: Rybaltovsky, A.; Popov, S.; Lipatov, D.; Umnikov, A.; Abramov, A.; Morozov, O.; Ryakhovskiy, D.;

Voloshin, V.; Kolosovskii, A.;

Vorob'ev, I.; et al. Photosensitive Yb-Doped Germanophosphosilicate Artificial Rayleigh Fibers as a Base of Random Lasers. Fibers 2021, 9, 53. https://doi.org/10.3390/ fib9090053

Academic Editor: Martin J. D. Clift

Received: 10 July 2021

Accepted: 23 August 2021

Published: 1 September 2021

Publisher's Note: MDPI stays neutral with regard to jurisdictional claims in published maps and institutional affiliations.

Copyright: (c) 2021 by the authors. Licensee MDPI, Basel, Switzerland. This article is an open access article distributed under the terms and conditions of the Creative Commons Attribution (CC BY) license (https:/ / creativecommons.org/licenses/by/ $4.0 /)$.
Abstract: Asingle-mode $\mathrm{Yb}$-doped germanophosphosilicate fiber with ultra-low optical losses (less than $2 \mathrm{~dB} / \mathrm{km}$ ) was fabricated by means of the MCVD method utilizing an all-gas-phase deposition technique developed "in house". The absorption and luminescent spectral properties of the fiber were thoroughly studied. The photosensitivity of the pristine (non-hydrogenated) fiber to $248 \mathrm{~nm}$ laser radiation was confirmed by means of fiber Bragg grating (FBG) inscription directly during the drawing process. The random single-frequency lasing at the 1060-nm-wavelength obtained in the 21-m-long fiber with an array of weak FBG was reported. The developed laser slope efficiency in the backward-pumping scheme was measured as high as $32 \%$.

Keywords: ytterbium-doped optical fiber; phosphosilicate fiber; photosensitivity; fiber Bragg gratings array; random laser; single-frequency fiber laser

\section{Introduction}

Nowadays, the development of single-frequency fiber lasers (SFLs) is of great interest for telecommunications, metrology, spectroscopy, and instrument engineering (lidars, distributed acoustic and seismic sensor systems). In fact, the majority of such lasers are based on a short Fabry-Perot cavity of only a few centimeters long, which is the fundamental requirement for the generation of a single longitudinal mode in it [1]. To ensure the efficient absorption of pump radiation in such short laser cavities, active optical fibers with a relatively high concentration of active ions in the glass core are used [2,3]. Slope efficiency of SFLs typically does not exceed 30\% [4]. Therefore, since intense absorption of pump radiation in a short fiber section occurs, a significant heat release appears in a small glass volume, and stable laser operation of the short cavity must be maintained using external cooling circuits. Another undesirable consequence of a high concentration of active ions in a fiber core is the effect of the spontaneous switching of the laser output beam from continuous (CW) to pulsed mode and vice versa, the mechanism of which is associated with up-conversion processes inside ion clusters [5,6].

The incoherent "mirrorless" random laser cavity is a promising development for single-frequency operation in comparison with the conventional Fabry-Perot cavity [7]. In fact, random fiber lasers are able to produce light with unique performance characteristics without imposing stringent requirements on the cavity configuration. Current trends in 
random fiber lasers are associated with evolution of long (10-100 km) cavities based on SMF-28 fibers to short laser configurations based on short ( 10m) FBG array fibers referred to as artificial Rayleigh fibers [8,9]. The use of artificial Rayleigh fibers, as the cavity of a random laser not only reduces the cavity length to acceptable values, but also provides the spectral selection of lasing generation at the reflection wavelength of the FBG array. In the latter case, a promising direction is the inscription of the FBG arrays in an optical fiber-doped with rare-earth elements such as erbium, ytterbium, etc. This provides greater spectral and signal level stabilization of laser radiation because the dynamic gratings forming exactly in the laser's cavity $[9,10]$.

A notable feature of the technique for creating such an array of FBGs of the same type is the possibility of inscribing them directly during the fiber drawing process with the help of phase mask technique and excimer laser UV-radiation. In addition, after applying a polymer coating over the fiber with gratings inscribed in it, its mechanical strength does not differ from that of a conventionally drawn fiber. However, it should be noted that the optical fiber chosen for inscribing FBGs during the drawing process should have a sufficient initial photosensitivity [8]. In [9], the possibility of fabricating a laser cavity from an array of FBGs inscribed in a segment of the Er-doped fiber with a relatively low concentration of $\mathrm{Er}^{3+}$ ions (Er absorption $\sim 20 \mathrm{~dB} / \mathrm{m}$ at a wavelength of $1530 \mathrm{~nm}$ ) was demonstrated. The developed laser stably generated single-frequency radiation at a wavelength of $1547.6 \mathrm{~nm}$ with a narrow line (width less than $1 \mathrm{kHz}$ ). At a pump radiation power of $250 \mathrm{~mW}$, which was 2.5 times higher than the lasing threshold, the laser operation became an almost continuous wave (the pulsation amplitude was less than $\sim 2 \%$ ). Thus, the use of extended lengths of optical fibers weakly doped with rare-earth dopants as a base for creating of SFL cavities will make it possible in the future to minimize or even get rid of the problem of the undesirable Self-Q-Switch mode appearance as well as the problem of excessive heat release and associated temperature instability. The output characteristics of a single-frequency Er-doped Random FBG laser are presented in [8], which are at least not inferior to lasers with a classical Fabry-Perot cavity, and make it a promising alternative to the "traditional" SFLs.

This research work is devoted to the development of a single-frequency Random FBG laser designed to operate in the wavelength range of $\sim 1.06 \mu \mathrm{m}$. For the purpose of this research, a special photosensitive $\mathrm{Yb}$-doped fiber based on a novel germanophosphosilicate glass core composition co-doped with a low concentration of $\mathrm{Yb}^{3+}$ ions was fabricated utilizing the MCVD method and an original all-gas-phase deposition technique developed "in house". In this paper, the fiber fabrication technique as well as the active fiber parameters and core glass properties were investigated in detail.

\section{Materials and Methods}

The fiber preform was fabricated by utilizing an all-gas-phase deposition technique and the MCVD fabrication method and facility. The $\mathrm{Yb}(\text { thd })_{3}$ chelate precursor was thermostat controlled at a temperature of $149{ }^{\circ} \mathrm{C}$ to secure an acceptable vapor pressure. The preform core glass was synthesized by means of an original technique where the separate deposition of glass host components and the active dopant was implemented; the deposition technique is described in detail in our previously published works [11-13]. At first stage of the technical process, a porous layer of the $\mathrm{GeO}_{2} / \mathrm{P}_{2} \mathrm{O}_{5} / \mathrm{SiO}_{2}$ composition was deposited at a reduced temperature of $\sim 1400{ }^{\circ} \mathrm{C}$. Then, $\mathrm{Yb}(\text { thd })_{3}$ vapors delivered by a carrier gas (argon) via delivery lines and a rotary seal (the units were heated up to $\sim 200{ }^{\circ} \mathrm{C}$ to prevent the vapors preliminary deposition) mixed with oxygen in the reference silica tube (Heraeus F300, outer diameter $15 \mathrm{~mm}$, wall thickness $1.3 \mathrm{~mm}$ ). The $\mathrm{Yb}_{2} \mathrm{O}_{3}$ particles formed in the hot zone (since $\mathrm{Yb}(\text { thd })_{3}$ thermo-decomposition process occurs) were deposited on the inner surface of the silica tube over the deposited germanophosphosilicate porous layer, while the outer surface of the deposition tube was heated by an oxy-hydrogen burner flame at a temperature of $\sim 1300{ }^{\circ} \mathrm{C}$. Then, the $\mathrm{Yb}_{2} \mathrm{O}_{3} / \mathrm{GeO}_{2} / \mathrm{P}_{2} \mathrm{O}_{5} / \mathrm{SiO}_{2}$ glass layer was fully sintered at a temperature of $\sim 1950{ }^{\circ} \mathrm{C}$ into transparent glass in an oxygen atmosphere with the 
addition of $\mathrm{CCl}_{4}$ flow to remove the majority of the hydrogen-containing impurities formed at the previous gas-phase impregnation stage. A passive layer of the $\mathrm{GeO}_{2} / \mathrm{P}_{2} \mathrm{O}_{5} / \mathrm{SiO}_{2}$ glass composition with a refractive index adjusted to that of the doped glass layer was deposited on top of the $\mathrm{Yb}$-doped glass. Once the deposition of the core material finished, the temperature of the oxy-hydrogen burner was increased to above $2000{ }^{\circ} \mathrm{C}$, and the tube preform was collapsed to maintain an extremely small inner capillary of $\sim 1 \mathrm{~mm}$. Then, the passive layer depleted in $\mathrm{P}_{2} \mathrm{O}_{5}$ and $\mathrm{GeO}_{2}$ (evaporated during high temperature collapse process) was almost completely etched with the help of a $\mathrm{C}_{2} \mathrm{~F}_{3} \mathrm{Cl}_{3}$ gas flow. At final stage of the technical process, the tube preform was eventually consolidated into a solid rod at a relatively low temperature $\left(1950^{\circ} \mathrm{C}\right)$ to prevent the excessive evaporation of volatile components and to minimize a central dip the core. Thus, the fiber preform with a homogeneous $\mathrm{Yb}$-doped germanophosphosilicate core glass was manufactured.

To measure the core-cladding refractive index difference in the fabricated preform $\left(\Delta \mathrm{n}_{\text {core-clad }}\right)$ a Photon Kinetics P2610 preform analyzer was used. The elemental composition of the core glass was determined using X-ray analyzer JEOL 5910LV in the multimode fiber.

Multi-mode (core diameter $\sim 20 \mu \mathrm{m}$ ) and single-mode (core diameter $\sim 6 \mu \mathrm{m}$ ) fibers with an outer diameter of $125 \mu \mathrm{m}$ were drawn from the fabricated preform. Directly during the fiber drawing process, weakly reflecting FBGs were inscribed in the single-mode fiber core using an experimental setup based on an Optosystems CL-5100 KrF excimer laser generating pulsed UV radiation with a wavelength of $248 \mathrm{~nm}$. The inscribing technique for an array of weakly reflecting FBGs distributed over the fiber length and the setup scheme are described in detail in $[14,15]$. At a constant fiber drawing speed, the distance between the individual gratings is determined by the laser pulse repetition rate. In this work, at a fixed drawing speed of $6 \mathrm{~m} / \mathrm{min}$, two FBGs arrays were inscribed, which were located in the fiber sections that were each $100 \mathrm{~m}$ long. An array of N1 gratings inscribed at a pulse repetition rate of $10 \mathrm{~Hz}$ and using a phase mask with a periodof $729.5 \mathrm{~nm}$ covered the entire length of the fiber segment ( $100 \%$ of the fiber length was filled with gratings). An array of $\mathrm{N} 2$ gratings only filled half of the length of the fiber section with gratings ( $50 \%$-filling); to inscribe these gratings, in contrast to array N1, a phase mask with a period of $1070 \mathrm{~nm}$ and a pulse repetition rate of $5 \mathrm{~Hz}$ were used. The length of each grating in both of the arrays was $10 \mathrm{~mm}$, and the UV irradiation dose was $400 \mathrm{~mJ} / \mathrm{cm}^{2}$, which corresponds to the single pulse energy density.

The spectral characteristics of the inscribed FBGs arrays were studied by analyzing their reflection spectra. Thus, to obtain the reflection spectra of the N1 array, a standard technique was used, which was based on recording the radiation spectrum from a broadband source (superluminescent diode) reflected by the grating using an optical spectrum analyzer $[14,16]$. In this work, we used a Yokogawa AQ6370D optical spectrum analyzer with an optical resolution of $0.05 \mathrm{~nm}$ in the wavelength range of $\sim 1 \mu \mathrm{m}$. The reflection spectra of the N2 array were studied using a Luna 4400 precision reflectometer designed for the Optical Frequency Domain Reflectometry (OFDR) analysis of an optical signal reflected in a fiber in a narrow spectral range of 1530-1570 nm [17]. Compared to the optical spectrum, in which it is impossible to separate the contribution from single FBGs with close reflection wavelengths, the analysis of reflectograms (OFDR traces) allows one to obtain information about each of the inscribed FBGs in the fiber sample. However, the possibility of using OFDR in practice has hardware limitations; namely, it is typically a narrow spectral range of the reflectometer's sensitivity.

Apiece of the $\mathrm{Yb}$-doped fiber containing the array of the N1 gratings was investigated for possible use as a laser resonator. In the present work, we used a "backward-pumping" of the laser cavity, which was similar to the pumping scheme of a single-frequency $\mathrm{Yb}$ doped fiber laser that was earlier described in detail in our previous work [18]. The schematic diagram of currently used laser pumping setup is shown on Figure 1. The radiation of a QFLD-905-200S pump laser diode with an output wavelength of $907 \mathrm{~nm}$ was injected through the corresponding port of the 915/1064 filter-based wavelength division 
multiplexer (FWDM) into a segment of the Yb-doped fiber with the array of $\mathrm{N} 1$ gratings inscribed in its core. An oblique cleavage was made at the opposite end of the active fiber section in order to prevent possible influence of the reflected radiation on the stability of the laser generation. A Yokogawa AQ6370D spectrum analyzer and a JDSU OLP-85 power meter were used to record the optical spectrum of the laser radiation and to measure the laser output power and the launched pump power.

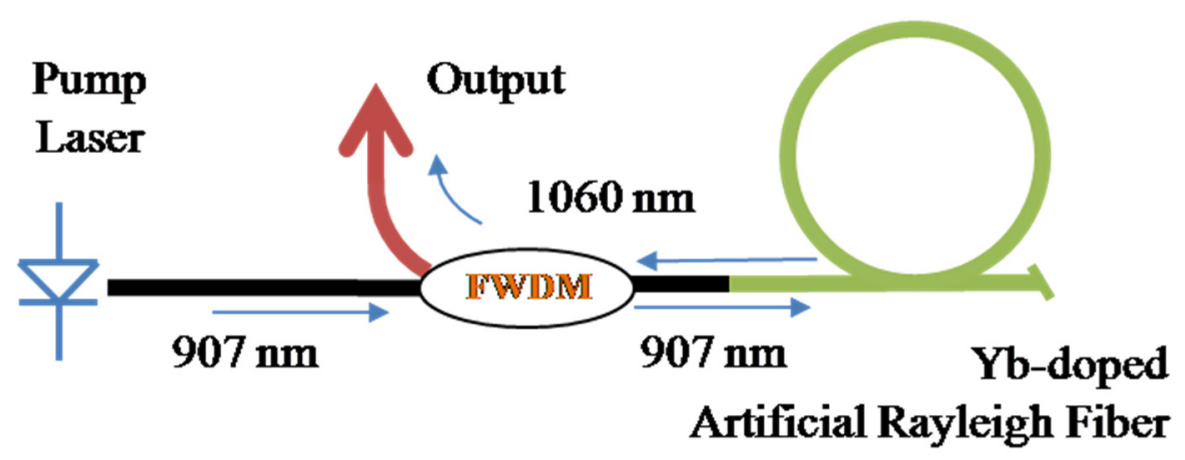

Figure 1. Schematic diagram showing the laser pumping setup.

\section{Results}

For convenience, we have divided the experimental results presented in this work into two major parts. In the first part, the physicochemical, optical, and waveguide characteristics of the active fiber core are discussed. In the second one, the characteristics of the random-FBG laser based on this fiber are considered.

\subsection{Optical and Material Properties of the Developed Active Fiber}

The results of measurementsof the refractive index profile (RIP) in the fabricated fiber preform and the radial distribution of the main glass host dopants in the fiber core, $\mathrm{P}_{2} \mathrm{O}_{5}$ and $\mathrm{GeO}_{2}$, are presented in Figure 2a, b, respectively. The RIP (Figure 2a) has a narrow dip in the core center, the nature of which is the partial loss of $\mathrm{GeO}_{2}$ and $\mathrm{P}_{2} \mathrm{O}_{5}$ components due to evaporation during the high-temperature collapse process of the tube preform [19]. At the same time, it should be noted that the width and depth of the central dip turned out to be noticeably smaller than the dip in preforms with a fluorophosphosilicate glass core manufactured by the same MCVD deposition method [12,13]. As we can see from Figure $2 \mathrm{~b}$, in the fiber core region (the range $20-40 \mu \mathrm{m}$ along the $\mathrm{X}$ axis), the glass host dopant concentration is $\sim 4 \mathrm{~mol} \%$ of $\mathrm{P}_{2} \mathrm{O}_{5}$ and $\sim 3 \mathrm{~mol} \%$ of $\mathrm{GeO}_{2}$. In addition to the core region, a small amount of $\mathrm{P}_{2} \mathrm{O}_{5}(\sim 1.5 \mathrm{~mol} \%)$ is also present in the reflective cladding region (fluorophosphosilicate reflective cladding was deposited in the fabricated preform). The $\mathrm{Yb}$ dopant content is below the detection limit of the used $\mathrm{X}$-ray analyzer, i.e., less than $0.1 \mathrm{~mol} \%$. Consequently, the fiber RIP refractive index profile was completely formed by host glass dopants, namely $\mathrm{P}_{2} \mathrm{O}_{5}$ and $\mathrm{GeO}_{2}$. 


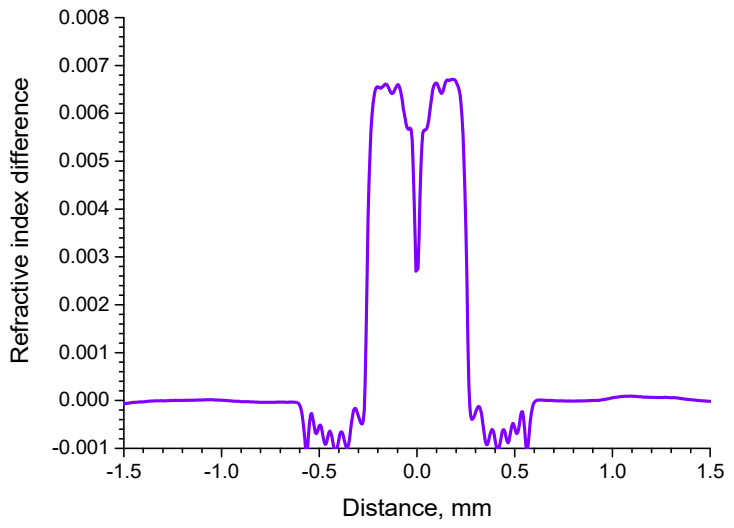

(a)

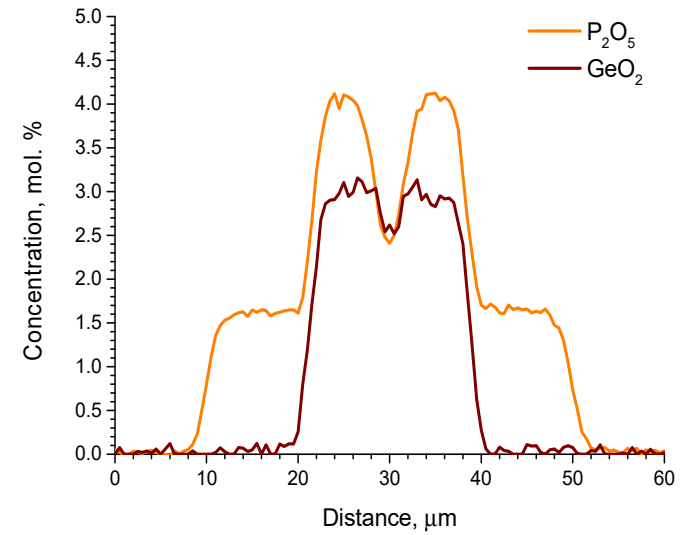

(b)

Figure 2. The fiber core glass characteristics: (a) refractive index profile (RIP) measured in the fiber preform; (b) radial elemental distribution of the glass host dopants measured in the drawn multi-mode fiber.

Optical loss spectra of a single-mode fiber drawn from the fabricated preform are shown in Figure 3. The absorption intensity of the $\mathrm{Yb}^{3+}$ ions in the fiber at a wavelength of $975 \mathrm{~nm}$ was measured $\sim 22 \mathrm{~dB} / \mathrm{m}$ (Figure 3a). At the pump radiation wavelength of $907 \mathrm{~nm}$, the absorption was much lower, only $\sim 3.7 \mathrm{~dB} / \mathrm{m}$. However, this active dopant concentration makes it possible to achieve a more uniform level of a $\mathrm{Yb}^{3+}$ ion inversion population in the cavity of the Random FBG laser, which typically has a length of at least several meters. In this work, to fabricate the cavity of such a laser, we used an array of N1 FBGs inscribed using a phase mask with a period of $729.5 \mathrm{~nm}$, therefore having the maximum reflection wavelength of about $1060 \mathrm{~nm}$. As it can be seen from the absorption spectrum in Figure 3b, the absorption value at this particular wavelength is $\sim 0.03 \mathrm{~dB} / \mathrm{m}$, which is quite acceptable for the cavity of a Random FBG laser. It should be noted that the extremely low level of losses far from the absorption maximum of the $\mathrm{Yb}^{3+}$ ions in the investigated fiber (we measured optical losses less than $2 \mathrm{~dB} / \mathrm{km}$ at a wavelength of $1200 \mathrm{~nm}$ ) also indicates the absence of detrimental impurities in the developed fiber and confirms a highly homogeneous distribution of the host glass dopants $\left(\mathrm{P}_{2} \mathrm{O}_{5}\right.$ and $\left.\mathrm{GeO}_{2}\right)$ in the silica glass of the fiber core.

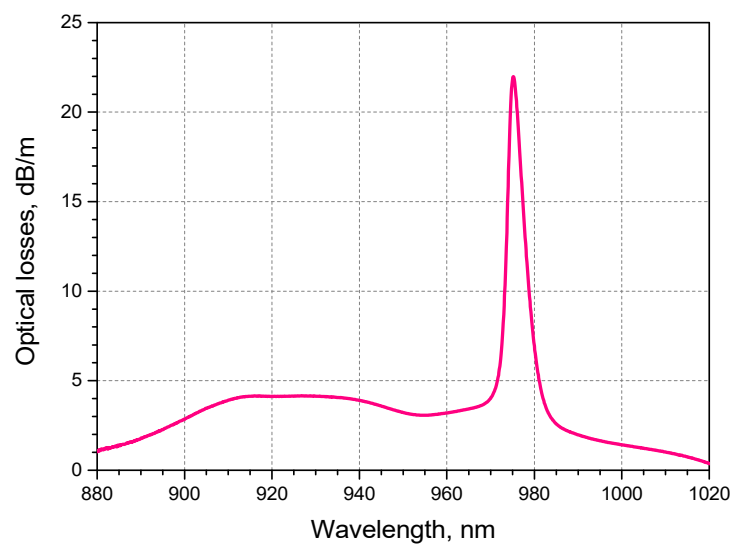

(a)

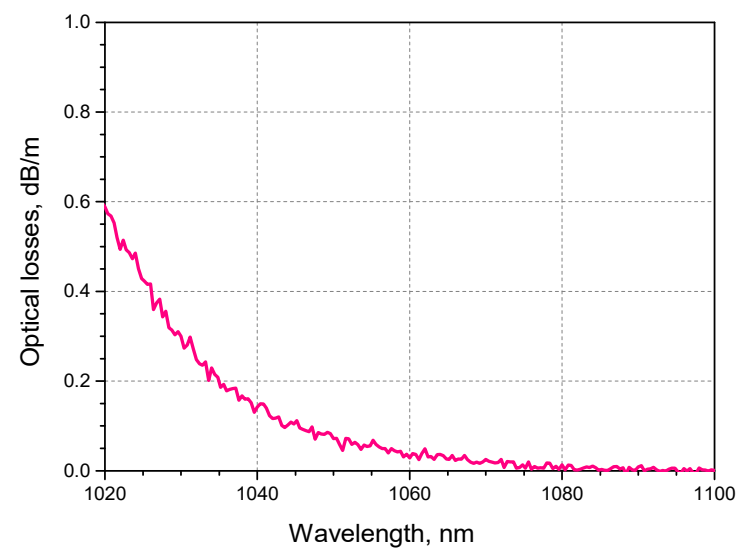

(b)

Figure 3. The optical absorption spectraof a single-mode fiber: (a) in the spectral range of 880-1020 nm; (b) in the spectral range of $1020-1100 \mathrm{~nm}$. 


\subsection{Random FBG Fiber Laser Characteristics}

The quality and contrast evaluation of the FBGs inscribed in the single-mode fiber developed in this work was performed by analyzing the OFDR traces of the array of N2 gratings, a fragment of which is depicted in Figure 4. Each of the maximums in the given fragment of the OFDR trace was obtained as a result of reflection of the probe signal from a separate FBG. The signal level of $-100 \mathrm{~dB} / \mathrm{mm}$ corresponds to Rayleigh scattering in the fiber. The difference between the maximum of the signal and the level of Rayleigh scattering was taken as the grating contrast value. It can be seen that the contrast of all of the gratings is approximately the same and typically exceeds $50 \mathrm{~dB}$, which is two orders of magnitude higher than the contrast of gratings inscribed using the same technique in a standard germanosilicate fiber [14]. The higher contrast value of the FBGs in the fabricated fiber with germanophosphosilicate glass core indicates the developed glass high photosensitivity to 248-nm-wavelength UV laser radiation.

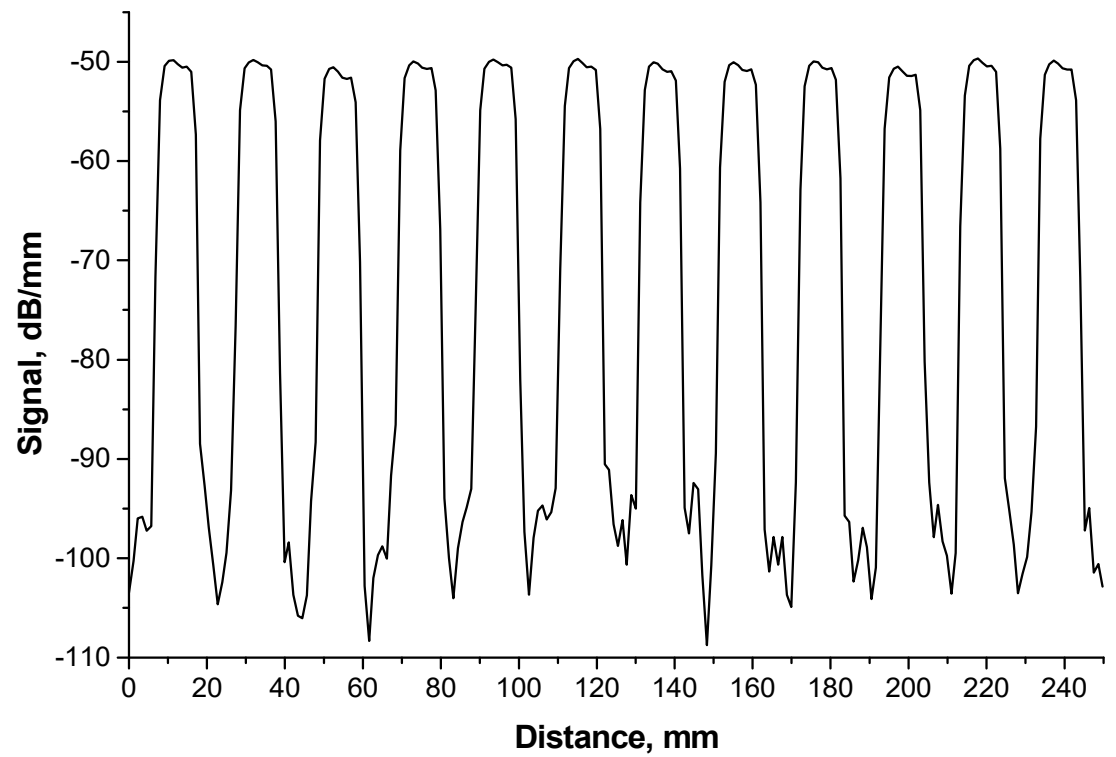

Figure 4. Measured OFDR trace of the FBG array N 2.

When evaluating the optimal cavity length of the Random FBG laser, it was assumed that the array of N1 gratings inscribed at the same value of the UV radiation dose per grating $\left(400 \mathrm{~mJ} / \mathrm{cm}^{2}\right)$ was at least as good as the array of the N2 gratings in terms of its contrast and homogeneity. The reflection spectrum of the entire array of $\mathrm{N} 1$ gratings is depicted in Figure 5 (Curve " 1 "). The signal intensity at the peak with maximum reflection corresponds to a level of $-65.2 \mathrm{dBm}$. As it can be seen, the maximal reflection of most gratings is located in a rather narrow spectral region: $1060.2 \pm 0.05 \mathrm{~nm}$. This means a relatively high selective ability of the array of the gratings in respect to the working length of the laser cavity.

Once this array of gratings was connected to the pump radiation source, lasing was detected with a narrow peak near the wavelength of $1060.15 \mathrm{~nm}$ (Figure 5, Curve " 2 "). The lasing wavelength here corresponds the position of the maximal reflection of the array of gratings. In fact, the presence of a single narrow peak in the laser spectrum, which has a width comparable to the maximal resolution of the spectrum analyzer $(0.05 \mathrm{~nm})$, confirms a single-frequency laser operation mode. The optimal length of the laser cavity, at which point the output power had not decreased yet, was found at the maximal allowed pump power value of $100 \mathrm{~mW}$ by the gradual shortening of the length of the active fiber with an array of gratings inscribed in it and eventually amounted to $21 \mathrm{~m}$. For this length, the lasing threshold was found to be $25 \mathrm{~mW}$ of pump power. 


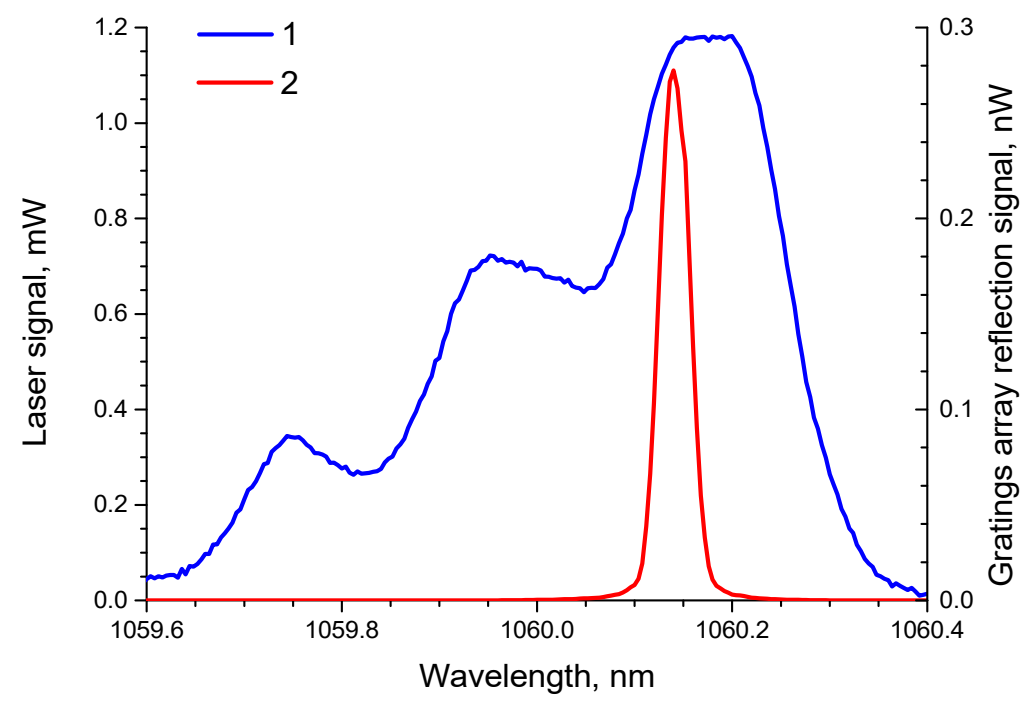

Figure 5. The array of N1 FBGs reflection spectrum (Curve "1") and Random FBG laser emission spectrum (Curve "2") measured at the pump power value of $30 \mathrm{~mW}$.

It was found that, over the entire range of pump power values available in our experiments (up to $100 \mathrm{~mW}$ ), the developed laser was working strictly in a CW mode. The absence of the signs of excitation of the pulsed lasing regime is explained by the simultaneously high and uniform $\mathrm{Yb}^{3+}$ ion inversion population level along the entire length of the laser cavity, which is difficult to achieve in cavities based on highly Yb-doped fibers $[5,20]$. The dependence of the output power on the pump power introduced into the cavity is shown in Figure 6. According to the results of the measurements, the slope efficiency value was $\sim 32 \%$. The maximal achieved output power of $20 \mathrm{~mW}$ corresponds to the level of currently commercially available single-frequency semiconductor lasers.

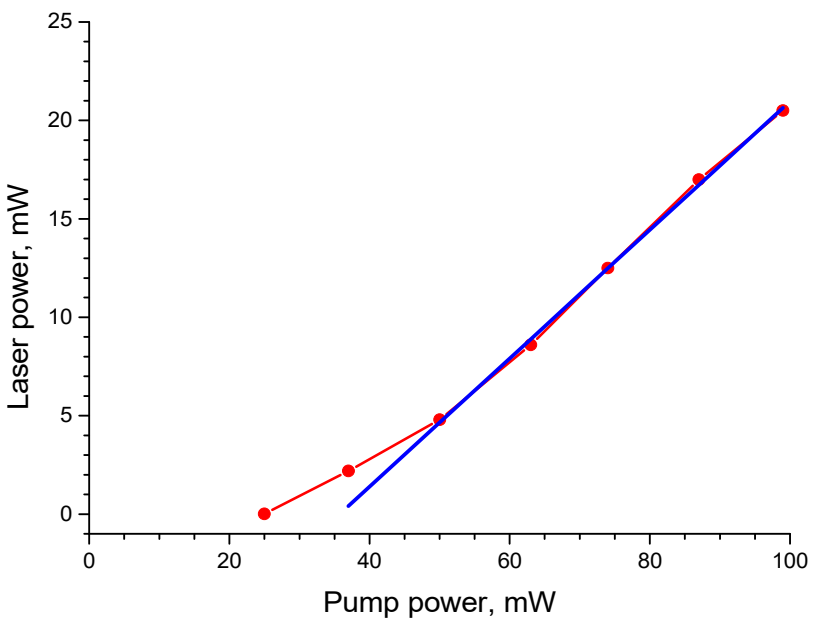

Figure 6. Random FBG laser output power versus launched pump power.

\section{Conclusions}

In summary, we reportedarandom single-frequency lasing in the vicinity of $1060 \mathrm{~nm}$ wavelength spectral range that was achieved for the first time using a specially developed $\mathrm{Yb}$-doped germanophosphosilicate artificial Rayleigh optical fiber. The fiber preform was fabricated by means of the MCVD method and by utilizing an original all-gas-phase deposition technique developed "in house". The fiber core glass co-doped with $\mathrm{P}_{2} \mathrm{O}_{5}$ and $\mathrm{GeO}_{2}$ was thoroughly investigated and was found to demonstrate improved photosensitivity to 248-nm-laser radiation. This fact has opened up the possibility of manufacturing an effective random-laser cavity directly during the fiber drawing process by means of 
inscribing an array of weak FBGs uniformly distributed along the fiber length. As a result, the developed fiber laser with a 21-m-long cavity demonstrated the slope efficiency of $32 \%$ in the case of using a backward $907 \mathrm{~nm}$ pumping scheme.

Author Contributions: Conceptualization, A.R., S.P. and D.L.; methodology, V.V., A.K., O.B. and Y.C.; software, O.M.; investigation, A.R., S.P., A.A., I.V. and D.R.; data curation, S.P. and Y.C.; writing-original draft preparation, A.R., S.P. and D.L.; writing-review and editing, A.U. and O.B.; supervision, S.P. and Y.C.; project administration, A.R. and D.L. All authors have read and agreed to the published version of the manuscript.

Funding: This research was funded by the Russian Foundation for Basic Research, grant number 20-08-00822 A.

Institutional Review Board Statement: Not applicable.

Informed Consent Statement: Not applicable.

Data Availability Statement: Not applicable.

Acknowledgments: This work was partly conducted within the framework of the state task.

Conflicts of Interest: The authors declare no conflict of interest.

\section{References}

1. Barmenkov, Y.O.; Zalvidea, D.; Torres-Peiró, S.; Cruz, J.L.; Andrés, M.V. Effective length of short Fabry-Perot cavity formed by uniform fiber Bragg gratings. Opt. Express 2006, 14, 6394-6399. [CrossRef] [PubMed]

2. Mo, S.; Xu, S.; Huang, X.; Zhang, W.; Feng, Z.; Chen, D.; Yang, T.; Yang, Z. A 1014 nm linearly polarized low noise narrowlinewidth single-frequency fiber laser. Opt. Express 2013, 21, 12419-12423. [CrossRef] [PubMed]

3. Yang, C.; Zhao, Q.; Feng, Z.; Peng, M.; Yang, Z.; Xu, S. 1120 nm kHz-linewidth single-polarization single-frequency Yb-doped phosphate fiber laser. Opt. Express 2016, 24, 29794-29799. [CrossRef] [PubMed]

4. Fu, S.; Shi, W.; Feng, Y.; Zhang, L.; Yang, Z.; Xu, S.; Zhu, X.; Norwood, R.A.; Peyghambarian, N. Review of recent progress on single-frequency fiber lasers. J. Opt. Soc. Am. B 2017, 34, A49-A62. [CrossRef]

5. Kir'yanov, A.V.; Barmenkov, Y.O. Self-Q-switched Ytterbium-doped all-fiber laser. Laser Phys. Lett. 2006, 3, 498-502. [CrossRef]

6. Smirnov, A.M.; Bazakutsa, A.P.; Chamorovskiy, Y.K.; Nechepurenko, I.A.; Dorofeenko, A.V.; Butov, O.V. Thermal switching of lasing regimes in heavily doped Er3+ fiber lasers. ACS Photonics 2018, 5, 5038-5046. [CrossRef]

7. Fotiadi, A.A. Random lasers: An incoherent fibre laser. Nat. Photonics 2010, 4, 204-205. [CrossRef]

8. Popov, S.M.; Butov, O.V.; Chamorovskiy, Y.K.; Isaev, V.A.; Kolosovskiy, A.O.; Voloshin, V.V.; Vorob'ev, I.L.; Vyatkin, M.Y.; Mégret, P.; Odnoblyudov, M.; et al. Brillouin lasing in single-mode tapered optical fiber with inscribed fiber Bragg grating array. Results Phys. 2018, 9, 625-627. [CrossRef]

9. Popov, S.M.; Butov, O.V.; Bazakutsa, A.P.; Vyatkin, M.Y.; Chamorovskii, Y.K.; Fotiadi, A.A. Random lasing in a short Er-doped artificial Rayleigh fiber. Results Phys. 2020, 16, 102868. [CrossRef]

10. Lobach, I.A.; Drobyshev, R.V.; Fotiadi, A.A.; Podivilov, E.V.; Kablukov, S.I.; Babin, S.A. Open-cavity fiber laser with distributed feedback based on externally or self-induced dynamic gratings. Opt. Lett. 2017, 42, 4207-4210. [CrossRef]

11. Lipatov, D.S.; Guryanov, A.N.; Yashkov, M.V.; Bubnov, M.M.; Likhachev, M.E. Fabrication of $\mathrm{Yb}_{2} \mathrm{O}_{3}-\mathrm{Al}_{2} \mathrm{O}_{3}-\mathrm{P}_{2} \mathrm{O}_{5}-\mathrm{SiO}_{2}$ opticalfibers with a perfect step-index profile by the MCVD process. Inorg. Mater. 2018, 54, 276-282. [CrossRef]

12. Khudyakov, M.M.; Lobanov, A.S.; Lipatov, D.S.; Abramov, A.N.; Vechkanov, N.N.; Guryanov, A.N.; Melkumov, M.M.; Bobkov, K.K.; Aleshkina, S.S.; Kochergina, T.A.; et al. Single-mode large-mode-area Er-Yb fibers with core based on phosphorosilicate glass highly doped with fluorine. Laser Phys. Lett. 2019, 16, 025105. [CrossRef]

13. Lipatov, D.S.; Lobanov, A.S.; Guryanov, A.N.; Umnikov, A.A.; Abramov, A.N.; Khudyakov, M.M.; Likhachev, M.E.; Morozov, O.G. Fabrication and characterization of Er/Yb co-doped fluorophosphosilicate glass core optical fibers. Fibers 2021, 9, 15. [CrossRef]

14. Zaitsev, I.A.; Butov, O.V.; Voloshin, V.V.; Vorob'ev, I.L.; Vyatkin, M.Y.; Kolosovskii, A.O.; Popov, S.M.; Chamorovskii, Y.K. Optical Fiber with Distributed Bragg-Type Reflector. J. Commun. Technol. Electron. 2016, 61, 639-645. [CrossRef]

15. Popov, S.M.; Butov, O.V.; Kolosovskii, A.O.; Voloshin, V.V.; Vorob'ev, I.L.; Isaev, V.A.; Vyatkin, M.Y.; Fotiadi, A.A.; Chamorovsky, Y.K. Optical fibres and fibre tapers with an array of Bragg gratings. Quantum Electron. 2019, 49, 1127-1131. [CrossRef]

16. Singh, N.; Jain, S.C.; Aggarwal, A.K.; Bajpai, R.P. Fibre Bragg grating using phase mask technology. J. Sci. Ind. Res. 2005, 64, $108-115$.

17. Soller, B.J.; Gifford, D.K.; Wolfe, M.S.; Froggatt, M.E. High resolution optical frequency domain reflectometry for characterization of components and assemblies. Opt. Express 2005, 13, 666-674. [CrossRef] [PubMed]

18. Butov, O.V.; Rybaltovsky, A.A.; Bazakutsa, A.P.; Golant, K.M.; Vyatkin, M.Y.; Popov, S.M.; Chamorovsky, Y.K. 1030 nm Yb ${ }^{3+}$ distributed feedback short cavity silica-based fiber laser. J. Opt. Soc. Am. B 2017, 34, A43-A47. [CrossRef] 
19. Bubnov, M.M.; Dianov, E.M.; Egorova, O.N.; Semjonov, S.L.; Guryanov, A.N.; Khopin, V.F.; DeLiso, E.M. Fabrication and investigation of single-mode highly phosphorus-doped fibers for Raman lasers. SPIE Proc. 2000, 4083, 12-22.

20. Smirnov, A.M.; Butov, O.V. All-fiber heavily ytterbium-doped, passively mode-locked laser with the $456 \mathrm{MHz}$ repetition rate. Opt. Lett. 2019, 44, 5065-5068. [CrossRef] [PubMed] 